International Journal of Language Education

Volume 5, Number 2, 2021, pp. 102-115

ISSN: $2548-8457$ (Print) 2548-8465 (Online)

Doi: https://doi.org/10.26858/ijole.v5i2.16284

\title{
Exploring TESOL Teachers' Perceptions of Project-Based Assessment in ELT Classroom
}

\author{
Navisatul Izzah \\ UPN Veteran Jawa Timur, Indonesia \\ Email:navisatul.ar@upnjatim.ac.id
}

Received: 27 November 2020

Reviewed: 3 January 2021-3 March 2021

Accepted: 5 May 2021

\begin{abstract}
This study explored the perceptions of TESOL teachers in Indonesia regarding the use of project-based assessment in their classrooms. As assessment has undergone massive development and shifting paradigms, there has been recognition for teachers to reconceptualize their assessment practice. There have been attempts made by some countries, including Indonesia, to introduce various assessment methods including project-based assessment. Since it has been introduced in Indonesia in 2016 through government documents, little is known about TESOL teachers' use of this assessment method. Furthermore, project-based assessment has mostly been used in the science classroom, but not in ELT classroom. Research study regarding the use of project-based assessment in ELT classroom and how TESOL teachers in Indonesia perceive the use of project-based assessment would therefore be valuable additions to the field. This study used a qualitative case study as its methodology to gain an in-depth understanding of the emerging issue. Four ELT teachers around Surabaya were interviewed about their project-based assessment practice. The findings of this study revealed that teachers highly value the use of project-based assessment in their classroom despite the challenges they encounter. Hence, some implications and directions for further studies are also provided.
\end{abstract}

Keywords: assessment method, classroom assessment, TESOL Teachers, project-based assessment, ELT in Indonesia

\section{Introduction}

There has been increasing recognition for the need to reconceptualise teachers' assessment practices (e.g. Balliro, 1993; Cirit, 2015; Dwyer, 2008; Gipps, 1994; Ortega \& Minchalla, 2017). As assessment has undergone massive development, the current trend of assessment highlights the shift from a testing and examination culture to an assessment culture, which is believed to be the primary vehicle for advancing teaching and learning (Dwyer, 2008; Gipps, 1994). Following the current trend, an attempt has been made by some countries, including Indonesia, to introduce a wider range of assessment methods that focus on educational assessment; for instance, the use of alternative assessment such as project-based assessment. Project-based assessment (also known as 'project') is an assessment method that involves long-term and open-ended activity that may take several days to complete (Dwyer, 2008). This assessment method is not new and has been used previously in some countries (USA, UK, India, etc.); however, the term is used very loosely and variously (e.g. Dwyer, 2008; Gipps, 1994; Shome \& Natarajan, 2013). Meanwhile, in Indonesia, 
this assessment method has just been introduced by the Ministry of Education and Culture through its Assessment Guidelines document in 2016. Consequently, the research studies related to the use of project-based assessment in the Indonesian context are very limited; hence, more scholarly works exploring this assessment method in Indonesia would be valuable additions to the field.

As teachers have a very central role in assessment, there has been recognition that discussing teachers' perceptions towards their assessment practice is imperative (Inbar-Lourie \& Donitsa-Schmidt, 2009). This research study was therefore conducted to explore how TESOL teachers perceive their role in the use of project-based assessment in the classrooms. The following research question shaped the inquiry for this study: How do the TESOL teachers perceive the use of project-based assessment in their classroom?

This question provided opportunities to explore how TESOL teachers use project-based assessment, the value of those experiences, and the feelings towards those practices. Concerning the research question, TESOL teachers' perceptions are conceptualized as their thoughts towards their practice, which are commonly influenced by their background, knowledge, and experience (Dewey, 1960; 1973). Project-based assessment, as mentioned earlier, refers to an assessment method that involves a set of activities to measure students' competence within a given time frame (Dwyer, 2008).

\section{Literature review}

This section presents a review of literature relevant to this study to contextualize it within existing knowledge emerging from research. The discussion will clarify the current position of the topic area which is about teachers' perceptions on project-based assessment and reveal the gap in knowledge this study addresses.

Assessment development

Assessment has undergone massive development, from psychometrics to a broader model of educational assessment, from testing and examination culture to an assessment culture (Herman, Aschbacher, \& Winters, 1992; Gipps, 1994). There have been several scholars that discuss this development (Gipps, 1994; Black, 1998; Black \& William, 1998; Brown, 1998; Dwyer, 2008; Popham, 2008) along with tremendous research studies in assessment which revealed that assessment is teachers' most demanding, complex, yet important task (Rogers, 1991; Black \& Wiliam, 1998a, 1998b; Stiggins, 2001). Following the development, there is currently a wider range of assessments used than a few decades ago; classroom assessment, oral assessment, written examination, standardized test, portfolio, task-based assessment, project-based assessment, and technology-based assessment (Mayrath, Clarke-Midura, Robinson, \& Schraw, 2011). Assessment, as the heart of education (the Task Group on Assessment and Testing [TGAT] report, 1998), has taken on a high profile and serve a wide range of purposes (Gipps, 1994): teachers and parents often use the information as the parameter of students' academic strengths and weaknesses, communities make a judgment of educational systems according to this, policymakers determine whether the school are up to scratch and it therefore also impacts on curriculum and pedagogy. These new forms and range of purposes for assessment indicate that assessment continues to develop as the paradigm always shifts following the era.

This research study focuses on TESOL teachers' perspective of one type of classroom assessment namely project-based assessment. Broadly speaking, classroom assessment widely covers the classroom activities such as interactions between teacher and students, and between students within the classroom learning environment (Moreland \& Jones, 2000). Such assessment 
is initially known as teacher assessment (Gipps,1994; Filer, 1995; Torrance \& Pryor, 1995) yet this term fails to involve the role of students which is also essential in the assessment process. Furthermore, classroom assessment is closely related to students' learning. This concept is widely accepted both within Indonesia (Ministry of Education and Culture) and internationally (Crooks, 1988; Gipps, 1994; Bell \& Cowie, 1997; Black, 1998; Black \& Wiliam, 1998). As classroombased assessment is an integral part of the teaching-learning process, this research study hence focuses on how teachers perceive the formative interactions and summative judgments within the classroom by using project-based assessment.

The purposes of assessment in EFL classrooms

In doing a classroom assessment, it is necessary to first decide the purpose of conducting the assessment. Some research studies (Cheng, Rogers, \& Wang, 2007; and Shome \& Natarajan, 2013) found that teachers are commonly influenced by their instructional context. For instance, in Cheng et. al. research study (2007), the findings indicate that the purpose of classroom assessment from one country to another tends to be different according to the instructors and the contexts. In their research, they further identified that the instructors in Canada conduct assessments to monitor the students' development and formally grade the students (Cheng, et.al., 2007). In Hongkong, it appears that the instructors conduct an assessment to formally document the students learning (Cheng, et.al., 2007). Meanwhile, in China, teachers conduct assessments to prepare students for a standardized tests (Cheng, et.al., 2007). Accordingly, the purposes of these assessments influence the way teachers do the assessment; whether the assessments are in the form of projects, oral presentations, or tests. In addition, the selection of these assessment methods is also influenced by some other factors such as teachers' prior knowledge, beliefs, experiences (McMillan, 2003; Cheng, et.al., 2007).

Teachers' and students' perceptions of assessment

According to the Conceptions of Assessment Inventory (COA-III), there are four common teachers' perceptions toward assessment practices. These conceptions were further used in several studies (such as in Brown \& Hirschfeld, 2005; Peterson \& Irving, 2008) as the theoretical framework for their research about students' perceptions of assessment practices. The first concept is about assessment as a tool to improve teaching practices and enhance students' learning. This appears to be confirmed by several research study findings (as in Black \& William, 1998; Crooks, 1998; Brown, 2004; Peterson \& Irving, 2008). Second, assessment is used for students' accountability. Concerning this statement, the findings from Brown (2004) and Peterson and Irving (2008) counter this common perception. For example, in Peterson and Irving's study (2008), the findings indicate that students are aware that assessment is for learning and improvement yet only little shows they independently acted on that information. In other words, they tend to put the responsibility on the teacher instead of their own. For instance, when they receive a poor grade, they are likely to think that the teacher is 'being mean' or 'does not like me' (Peterson and Irving, 2008). Third, assessment is closely related to the schools' accountability. In other words, assessment results are often used for judging whether the schools are doing their job (Firestone et al., 1998; Mehrens \& Lehmann, 1984; Butterfield et al., 1999; Smith et al., 1999). Furthermore, the acknowledgment of this concept is also confirmed by teachers in Brown's (2004) and students in Peterson and Irving's studies (2008). Fourth, assessment could be irrelevant to teaching and learning. In Brown's study (2004), this irrelevant conception is classified into three sub-factors (assessment is bad, assessment is ignored, and assessment is inaccurate). However, the finding 
shows that teachers reject and disagree with this conception (Brown, 2004). Meanwhile, from students' point of view, Peterson and Irving (2008) found that students claim assessment might be an irrelevant tool if it is unfair, less honest, and less relevant to their later life.

Project-based assessment as an alternative assessment

Despite the changing era and the shifting paradigm of assessment, there has also been dissatisfaction with the use of traditional assessment which often insufficiently demonstrates the learners' achievements and progress (Balliro, 1993). In other words, the traditional assessment is currently not suitable for supporting students' learning, and hence doing assessment beyond the traditional way is imperative (Cirit, 2015). There is currently a wider range of assessments used in educational practices than before. Some of them are beyond the traditional one or are commonly known as an alternative assessments. Alternative assessment is defined as non-traditional assessment which includes all types of assessment other than standardized, traditional tests (Barootchi and Keshavarz, 2002). In addition, Bailey (1998) mentioned that alternative assessment methods are perpetual within a protracted period, direct, and authentic. Cirit (2015) also argues that alternative assessment encourages students to explore the possibilities by drawing on their inferences, rather than focus on one right answer.

Many alternative assessment methods are currently widely known, including project-based assessment. Project-based assessment is defined by the Indonesian Ministry of Education and Culture (2016) as an assessment method that aims to measure students' skills through applying their knowledge to a project in a given time frame. Furthermore, this assessment method can be used to measure more than one basic competence in several different subjects at once (ibid.). In other words, teachers can work with other colleagues to conduct a project-based assessment. For example, TESOL teachers can collaborate with science teachers in assigning the students to make a report (in English) about students' observations towards an ecosystem at school.

According to the Ministry of Education and Culture (2016), project-based assessment involves a set of processes: planning, collecting data, analyzing and presenting data, and reporting the data. This aims to develop and monitor students' skills in planning, investigating, and analyzing their projects (ibid.). Furthermore, this assessment method can facilitate the students to demonstrate their knowledge and experiences about the topic, improving their skills in formulating questions, searching for information about the topic, doing fieldwork, and interviewing (ibid.). This process can be done as an individual task or as group work (ibid.). The final product of the project can also be used to communicate the findings; for instance, through the use of visual display or written report (ibid.). Examples of project-based assessment are investigating biodiversity, making food or drinks from fresh fruits, creating some dance movements according to the skill level and the music, etc. (ibid.).

Four aspects need to be considered by teachers in project-based assessment: management skills, relevancy, originality, innovation, and creativity (Ministry of Education and Culture, 2016). Management skills are defined as the students' skills in choosing the topic, searching for information, managing the time in doing the project as well as in writing the report (ibid.). Relevancy is related to how the students combine their knowledge, comprehension, and skills to reach the indicators of the required basic competencies (ibid.). Originality is indicated by how the students maintain the originality of the project by presenting their work (ibid.). Innovation and creativity are related to how the students create something new or unique in their project (ibid.).

Project-based assessment is, however, not always known as the appropriate way to assess students; there are also several criticisms found related to the use of this assessment method. For 
instance, as this assessment method is compulsory in India (NCF, 2005 in CCE framework), some teachers in India felt that only a few students would be motivated enough to complete the projects. The teachers in India further explained that this assessment method demanded the students do complicated work within the time constraints (Shome \& Natarajan, 2013). Nonetheless, some disconnections were found between what the teachers perceived and the policy document. Shome and Natarajan (2013) confirmed these disconnections by saying, the term project had become a part of teachers' everyday vocabulary, though their ideas of what constituted a project differed from the policy as well as each other. (p. 75)

Shome and Natarajan (2013) further explained that teachers tended to focus on what was to be done instead of how it was to be done. For example, teachers gave projects as a home assignment with a very limited time. Shome and Natarajan (2013) further analyzed that teachers had not read the policy document since "they knew only the fragments of what it contained, as seen by their responses in the interview" (p. 76). This phenomenon created some tensions in aligning the standards (the syllabus) and in designing the project-based assessment (Krajcik, McNeill, \& Reiser, 2008; Shome \& Natarajan, 2013). It is therefore no surprise if the use of project-based assessment created some tensions in India.

\section{Method}

Research design

Using a qualitative methodology, this study was further classified into a case study. The nature of a qualitative case study suited this research, which focused on teachers' perspectives. This was supported by some scholarly works, which stated that a case study is one of the most appropriate methods to be used in exploring teachers' beliefs and teaching practices (Pajares, 1992; Shome \& Natarajan, 2013). Furthermore, a case study allows researchers to explore phenomena such as thought processes and feelings (Strauss \& Corbin, 1998), which are very closely related to the research question in this study. Additionally, it enhances the researcher's ability to maintain the holistic and meaningful characteristics of real-life events (Yin, 2003), which was highly important in this research.

\section{Data collection instruments}

Research methods commonly follow the methodologies. In a qualitative case study, the use of interviews is the most prominent (Bryman, 2016) and thus it was used in this study. The use of interviews has also been prominent in some previous research studies about teachers' perceptions on assessment (e.g. Cheng et al., 2008; Pathak \& Intratat, 2012; Shome \& Natarajan, 2013; Van den Bergh, et.al, 2006). This study, therefore, used semi-structured interviews as its data collection method, based on several reasons. First, semi-structured interviews allow the researcher to gain the research data without overly limiting the interviewees' responses (Bryman, 2016). Second, this research had already had a clear focus since the beginning of the investigation. The semi-structured interviews, therefore, enhanced this research to address more specific issues. Third, this study had more than one participant. The semi-structured interview was, therefore, preferable to avoid the presence of unnecessary and abundant data. Furthermore, this interview type requires a list of the interview questions prepared by the researcher to manage the discussion in the interview (Bryman, 2016). Although the questions might not be as exact as the interview guide, the questions are by and large likely to use a similar wording (Bryman, 2016). Hence, according to the feasibility, the 
use of semi-structured interviews aimed to manage the interviews and to gain the data that are required for this qualitative case study research.

Population and samples

Regarding the research question, this qualitative case study used purposive sampling. Furthermore, since generalization was not a goal in this study, a non-probability sampling such as purposive sampling appears to be the most appropriate choice (Merriam, 1998). The purposive sampling was further classified using a snowball sampling approach. Snowball sampling is a technique in which the researcher approaches a small group of people relevant to the research questions (Bryman, 2016). Then, this small group invites other participants who have had experiences relevant to the research (Bryman, 2016). This technique aimed to bring the researcher into contact with a wider range of participants while maintaining the criteria of the participants involved. As Patton (2002) said, this technique is also known as network sampling due to the involvement of people who know people who know what the case is about to provide rich information related to the study.

Four ELT teachers (all female), called 'Deborah', 'Irene', 'Vivian' and 'Lily', from private schools around Surabaya, Indonesia were approached and willingly participated in this study. They are teachers for grades $7,8,9$, and 10 , respectively. They were chosen to participate because they fulfill the requirements for participating, having each been teaching for more than a year and having some experience in conducting project-based assessments. Before being TESOL teachers, these individuals pursued a Bachelor's degree in Education at the same university and studied the same major, which was English Education. Their schools have implemented the latest curriculum, Kurikulum 2013, which has also been affiliated with many schools across the country. However, the textbooks used are various and not compulsory books from Kurikulum 2013. Rather, they use another textbook, which is preferred by their schools.

The procedure of data collection

First, the researcher reached the participants by message to schedule the interviews. As Yin (2014) suggested, it is important to build rapport and gain trust; therefore, I made some casual conversations before talking about the research. Then, I clearly stated my research purpose again, asked if there was consent, explained the procedures of the interview, and ensured the participants that their confidentiality would be protected. The interviews were done by face-to-face meetings with the participants and every participant was interviewed separately, on different days. Transcribing data was done immediately after each interview. This aimed to avoid mixed data as well as helping the researcher in the process of transcription. The interviews were between 30-45 minutes for each participant. Upon the participant's consent, the interview was audio-recorded. The audio recordings were there to enhance the transcription process (Dyson \& Genishi, 2005; Merriam, 1998). Some notes were also taken to catch the important points that the participants made during the interviews.

Data analysis

This study used a semi-structured interview as its data generation method and hence the raw data was in the form of some interview transcripts. During the transcription process, a thematic 
analysis was used to extract the essential information both between and within the transcripts. Then, identification of relevant themes through coding each transcript was done. In other words, the data was broken down into some parts and given labels. Hence, the data had been managed and the transcripts were more accessible than only listening to the recordings. Moreover, through data coding, the researcher could also make sense of the data and build an initial interpretation.

The next step was reading the sorted data. The data was read interpretively and reflexively, rather than literally. This is in line with Mason (2002) who stated that researchers' interpretations of their data are influenced by the way the researchers see the world or the case (ontology perspective) and how the researchers think it can be known through the dimension in which they can capture and relate the meaning of it (epistemology perspective). Furthermore, reading the research data was not possible, because the "social world is always already interpreted and because what we see is shaped by how we see it" (Mason, 2002, p.149). An interpretive reading enhanced the researcher's ability to construct and generate the data according to what the researcher thinks the data means or represents (Mason, 2002). At this point, it is important to highlight that reading data interpretively did not mean that the data were entirely interpreted by the researcher. Rather, to some degree, it was a combination of both interviewees' and researcher's interpretations. Additionally, a reflexive reading complemented the interpretive reading by positioning the researcher's role and perspective during the data generation and interpretation (Mason, 2002).

To focus on answering the research questions, highlight the important points, and enhance the data analysis, the interview transcripts were transformed into a discussion in which both interpretation and reflection were presented. Subsequently, these sorted data were interpreted further and explored to obtain the meaning of the researched phenomena. Finally, the data were analyzed and linked with the previous relevant literature

\section{Result/Findings}

Teachers' project practices

Each teacher had their own belief in the factors that influenced them using the projectbased assessment. Two teachers contended that the use of project-based assessment has brought more enjoyment and excitement to their classroom than would have been the case if only doing written tests. A teacher conveyed that she was thinking about the other subjects before deciding on the assessment method she used. In contrast, another teacher acknowledged that she often used her personal beliefs and considerations in assessing the students. However, they all agreed that despite those considerations, they were thinking about their students, particularly in how to promote the students' learning.

Vivian: 'I have never known that conducting this assessment method can bring a lot of excitement in the classroom.'

Deborah: 'What I love from conducting a project-based assessment is my students' excitement of doing the project.'

There was one teacher who considered other subjects - whether the other subjects' teachers used the project-based assessment or not. She did not want her students to have a heavy workload because they have many projects to do. Therefore, when most teachers used the project-based 
assessment, she preferred assessing her students using a test, which she considered to be a less demanding task.

Irene: 'I am considering other subjects - whether those subjects are planning to use the project-based assessment or not. I am thinking about the burden that the students get. My students are not only studying English at school. Therefore, for me, it is highly important to discuss with other teachers before we made the yearly plan. What is the science teacher going to do? What is Bahasa Indonesia's teacher going to do? And if they are doing projects, I will use a test, then. The reason is simply that I want to alleviate my students' workloads, so they are less burdened.'

Meanwhile, the other teacher used personal beliefs and considerations in her assessment practice. She conveyed that she often felt unsatisfied whenever she had to assess her students' using a written test only, although she acknowledged that the use of a test can be helpful in some cases. In other words, she preferred using a variety of assessment methods, including project-based assessments and tests.

Lily: 'I am the one who feels empty when my students only did a written test. It is just so monotonous and boring. Although doing a written test is fine for some students, I am still unhappy.'

Generally, these four teachers conducted the project-based assessment for their summative assessments: at the end of the unit or chapter, mid-term assessment, and end-of-term assessment. Furthermore, most teachers also conducted the project-based assessment according to the learning material. There was also a teacher who integrated some learning materials into the project. For instance, Irene asked the year 8 students to make an e-magazine, which was an integration of some materials including descriptive, procedural, narrative, recounting, and anecdotal texts.

All teachers acknowledged that there were some hidden purposes in using the project-based assessment. Most teachers wanted an improvement in some skills; in particular, students' teamwork and collaborative skills and problem-solving skills. Deborah and Lily noted that their students tended to work with the same people in every project. It, therefore, encouraged them to team up the groups so that their students can work with everyone in the classroom, including with students with special needs. Likewise, Irene also wanted the students to collaborate with their peers and expected an improvement in students' problem-solving skills. Meanwhile, Vivian wanted to improve her students' confidence in speaking English and in doing formal presentations in front of the class.

In conclusion, it has been noted that teachers have various considerations before deciding on an assessment method to use. According to the teachers' assessment practice, the project-based assessment was not only used as a method to assess their students but also as a tool for teachers to improve their students' skills and build their students' character.

Teachers' views on project-based assessment

All teachers shared the same views about the project-based assessment. They all emphasized that doing a project-based assessment involved a long process for not only the students but also themselves. According to the teachers' explanations about their practice, there were at least four steps involved in carrying out the project-based assessment; teaching the material, preproject (preparation), project-making, and post-project. As mentioned, all teachers used project- 
based assessment as the summative assessment. Therefore, before doing the assessment, teachers first taught the students about some concepts in the learning material. After that, they informed the students about what they were going to do, monitored them during the project planning in the group discussions, gave them feedback about the project planning, and assessed them. In the process of project-making, the teachers each needed to play their role as facilitators in monitoring the students' progress, giving feedback, and motivating students to finish the project within the time constraints as well as assessing them. After the project-making phase, some teachers often required a presentation or exhibition of the project. In this phase, the teachers did an observation, gave feedbacks and rewards, and also assessed the students.

It can be noted that the project-based assessment involves a continuous monitoring or observation process, feedback, and assessment. Therefore, it is not surprising that some teachers contended that the project-based assessment is an assessment method that provides information about students that is both academic and non-academic.

Lily: 'The project-based assessment does not only focus on students' academic achievement. Rather, I can also focus on observing my students: how they collaborate with others and whether they are helpful or not.'

Furthermore, teachers also have positive views about the use of project-based assessment in their classrooms. Teachers agreed that they enjoyed using the project-based assessment as one of their assessment methods. In Vivian's context, the project-based assessment has even changed her students' perceptions about English.

Vivian: 'The project-based assessment has a big chance to increase students' interest in English. It is fun, out of the box, and not always about answering questions in a short answer test. I can see that my students started loving the English subject since then. Probably because it is not about a pencil, paper, and grammar anymore.'

In conclusion, these teachers generally have positive views about the use of project-based assessment. Nevertheless, they also acknowledged that project-based assessment involved a long process, especially in monitoring/observing, giving feedback, and assessing students.

Teachers' feelings on project-based assessment

Most teachers felt that the use of project-based assessment gave them satisfaction and happiness. Vivian and Deborah further explained that their satisfaction and happiness came from their students' excitement during the assessment process. Additionally, they witnessed that their students struggled with it, tried their best, and consequently presented impressive projects that were often beyond their expectations. The teachers also highlighted that project-based assessment allows integration of some language skills, such as writing and speaking skills.

Vivian: 'To be honest, I did not expect much from my students. But witnessing how they are struggling and try their best brings happiness. I also enjoy doing the project-based assessment because I can integrate and assess two language skills at once. I have no doubt, this assessment method is great, and I definitely will use this again on other occasions.'

Deborah: 'So far, in my case, my students are excited, and accordingly they produce impressive projects. They fulfill my expectations and I am very satisfied with the projects.' 
Deborah: 'Doing a project is not only about one skill but it is an integration of several skills.'

Similarly, Irene's happiness also came from her students, particularly in how the students overcame every obstacle they encountered during the project. In addition, she also noted that in the project, the students learned how to collaborate with their friends and managed the group and time so they could finish within the time constraints. Lily also confirmed Irene's argument by emphasizing how the project-based assessment is very beneficial in terms of observing students' characters instead of focusing on their results.

Irene: 'I am personally happy with this assessment method since my students learn how to overcome their problems, collaborate with their friends, and work in a group to finish the projects on time.'

Lily: 'If teachers want to focus on students' results and get numbers, I think the projectbased assessment is not a wise choice. But, in terms of understanding how your students are doing, how the students' characters are, and how they collaborate with their peers, this is very helpful.'

In conclusion, the findings of this study revealed that teachers are, overall, happy and satisfied with the use of project-based assessment in their ELT classroom due to the student's excitement and the students' impressive.

\section{Discussion}

Teachers' project practices

Each teacher selects their assessment method according to several factors, such as students, their personal beliefs, institutions, and curriculum. While some of the findings of this study confirm that teachers' assessment practices are influenced by their personal beliefs and their contexts (Cheng et. al., 2008; McMillan, 2003), the knowledge revealed in this study also informs that students can be the most influential factor towards the teachers' assessment practice.

The findings of this study also indicate that recent assessments are serving a wider range of purposes than before (Gipps, 1994). According to the teachers' assessment practice, the use of project-based assessment was not only used as a method to assess their students but also as a tool for teachers to improve students' skills and build students' character.

Teachers' views on project-based assessment

Teachers in this study conveyed their perceptions of using project-based assessment in their teaching practices. The findings showed that teachers have positive views about the use of projectbased assessment in their classrooms. The discussion in this section relates the findings to existing knowledge, which refers to the Conceptions of Assessment Inventory (COA-III), particularly in the four common perceptions of assessment: improve teaching and enhance learning; students' accountability; school accountability; and the irrelevance of assessment.

According to the analysis, teachers believed that the project-based assessment requires a long process and they fulfilled the concept of the assessment in improving teaching practices and enhancing students' learning. This knowledge confirms the existing knowledge by Black and 
William (1998), Crooks (1998), Brown (2004), Peterson and Irving (2008). In relation to the improvement of students' accountability, the findings in this study revealed that teachers acknowledged the improvement of students' accountability and perceived it to be one of the benefits of using the project-based assessment. This knowledge contradicts the existing knowledge in Brown (2004) and Peterson and Irving (2008). Concerning the third conception, the teachers acknowledged that school becomes one of the factors that influence their assessment practice, but the assessment practice that teachers do is not for the school's accountability. They further explained that the school merely gives autonomy to its teachers regarding the assessment practice. In other words, the knowledge revealed in this study is in contrast with Brown (2004) and Peterson and Irving (2008). The fourth concept about the irrelevance of assessment towards teaching and learning is also rejected by teachers in this study, concurring with Brown (2004) and Peterson and Irving (2008).

Teachers' feelings on project-based assessment

The findings of this study revealed that teachers are, overall, happy and satisfied with the use of project-based assessment in their ELT classroom. Some teachers conveyed that their happiness and satisfaction came from students' excitement in the process of project-based assessment, which consequently resulted in the impressive projects they produced. They further explained that the use of project-based assessment allowed them to assess two or more language skills at once. Furthermore, Irene said that her happiness came from the benefits that can be gained from the project-based assessment. She conveyed that she enjoyed using project-based assessment since she witnessed the students encountering problems during the project, collaborating with their friends, and managing the team. This is in line with Cirit (2015) and Holmes and Hwang (2014) that said project-based assessment improves students' teamwork skills, bonding between students, and critical thinking skills. Lily supports Irene's argument by emphasizing how the project-based assessment was very beneficial in terms of observing students' characters instead of merely focusing on students' results.

\section{Conclusion}

The findings of the study revealed that these four teachers' selection of the assessment method was according to various factors, such as students, their personal beliefs, institutions, and curriculum. Teachers further agreed that students' factors are on top of the other three reasons. Furthermore, teachers also believed that assessment has recently served a wider range of purposes. In this case, the teachers often use project-based assessment not only as a method to assess their students but also as a tool to improve student's skills and build students' character.

Overall, teachers have positive views regarding the use of project-based assessment in their classrooms. They contend that project-based assessment contributes to the improvement of their teaching, the enhancement of students' learning, and the improvement of students' accountability.

Understanding that teachers find using project-based assessment valuable and beneficial has implications for other teachers, teacher associations, and principals. Recognition of teacher authority regarding their assessment practice and recognition of teacher time spent in facilitating students throughout the process of assessment may help principals to reconfigure their expectations towards the assessment method that should be used.

The findings of this study are limited to the researched contexts and remain nontransferable. However, this study can still be used as initial research for further research or extended research. 
This study was conducted at several schools around Surabaya, East Java, Indonesia focusing on four ELT teachers' use of project-based assessment as one of their assessment methods. Future research may investigate ELT teachers' perceptions of project-based assessment in a wider range of environments and school levels. While this study took a qualitative perspective, future studies may take a broader view by inviting a larger number of participants to investigate the current trends among teachers in using a project-based assessment. This study is limited to teachers who have already implemented project-based assessments in the classroom. Future research may wish to broaden the context and investigate teachers who have not implemented project-based assessment.

Declaration of conflicting interest

The authors state that there is no conflict of interest concerning the publication of this article.

Funding acknowledgment

This research received no external funding.

\section{References}

Bailey, K. M. (1998). Learning about language assessment: Dilemmas, decisions, and directions. Pacific Grove, CA: Heinle \& Heinle.

Balliro, L. (1993) What kind of alternative? Examining alternative assessment. TESOL Quarterly, 27(3), 558-561. https://doi.org/10.2307/3587490

Barootchi, N., and Keshavarz, M. H. (2002). Assessment of achievement through portfolios and teacher-made tests. Educational Research,44(3), 279-288. https://doi.org/10.1080/00131880210135313

Black, P. (1998). Testing: Friend or Foe? Theory and Practice of Assessment and Testing. USA: Falmer Press.

Black, P. \& Wiliam, D. (1998a). Assessment and classroom learning. Educational Assessment: Principles, Policy and Practice, 5(1), 7-74. Retrieved from https://www.gla.ac.uk/t4/learningandteaching/files/PGCTHE/BlackandWiliam1998.pdf

Black, P. \& Wiliam, D. (1998b). Inside the black box: Raising standards through classroom assessment. Phi Delta Kappan, 80(2), 139-148. Retrieved from https://www.rdc.udel.edu/wp-content/uploads/2015/04/InsideBlackBox.pdf

Bell, B. F., \& Cowie, B. M. (1997). Formative assessment and science education: Research report of the learning in science project (Assessment). Hamilton: University of Waikato.

Brown, J. D. (1998). New ways of classroom assessment. USA: TESOL, Inc.

Brown, H. D. (2003). Language assessment: Principles and classroom practice. San Francisco, California: Longman.

Brown, G. T. L. (2004) Teachers' conceptions of assessment: implications for policy and professional development. Assessment in Education: Principles, Policy \& Practice, 11(3), 301-318. DOI: 10.1080/0969594042000304609

Brown, G. T. L., \& Hirschfeld, G. H. F. (2005). Secondary school students' conceptions of assessment. Conceptions of Assessment and Feedback Project. Auckland, NZ: University of Auckland.

Bryman, A. (2016). Social research methods (Fifth ed.). UK: Oxford University Press.

Butterfield, S., Williams, A. \& Marr, A. (1999). Talking about assessment: mentor-student dialogues about pupil assessment in initial teacher training. Assessment in Education, 6(2), 
225-246. https://doi.org/10.1080/09695949992883

Cheng, L., Rogers, W. T., \& Wang, X. (2008). Assessment purposes and procedures in ESL/EFL classrooms. Assessment and Evaluation in Higher Education, 33(1), 9-32. DOI: $10.1080 / 02602930601122555$

Cirit, N. C. (2015). Assessing ELT pre-service teachers via web 2.0 tools: Perceptions toward traditional, online and alternative assessment. The Turkish Online Journal of Educational Technology, 14(3), 9-19. Retrieved from https://www.learntechlib.org/p/161464/

Crooks, T. (1988). The impact of classroom evaluation practices on students. Review of Educational Research, 58(4), 438-481. DOI: 10.2307/1170281

Dewey, J. (1960). On experience, nature and freedom: Representative selections. R. J. Bernstein (Ed.). Indianapolis, IND: The Bobbs-Merrill Company.

Dewey, J. (1973). The philosophy of John Dewey. New York, NY: Putnam's Sons.

Dwyer, C.A. (2008). The future of assessment. New York: Taylor \& Francis Group.

Dyson, A.H., \& Genishi, C. (2005). On the case: Approaches to language and literacy research. New York: Teachers College Press.

Filer, A. (1995). Teacher assessment: Social process and social product. Assessment in Education, 2(1), 23-38. https://doi.org/10.1080/0969594950020103

Firestone, W. A., Mayrowetz, D. \& Fairman, J. (1998). Performance-based assessment and instructional change: the effects of testing in Maine and Maryland. Educational Evaluation and Policy Analysis, 20(2), 95-113. DOI: 10.2307/1164376

Gipps, C. V. (1994). Beyond testing: Towards a theory of educational assessment. London: Falmer Press.

Herman, J. L., Aschbacher, P. R., and Winters, L. (1992) A practical guide to alternative assessment. Alexandria, VA.: Association for Supervision and Curriculum Development.

Inbar-Lourie, O., \& Donitsa-Schmidt, S. (2009). Exploring classroom assessment practices: The case of teachers of English as a foreign language. Assessment in Education: Principles, Policy \& Practice, 16(2), 185-204. DOI: 10.1080/09695940903075958

Krajcik, J., McNeill, K. L., \& Reiser, B. J. (2008). Learning-goals-driven design model: developing curriculum materials that align with national standards and incorporate projectbased pedagogy. Science Education, 92(10), 1-32. https://doi.org/10.1002/sce.20240

Manouchehri, A., \& Goodman, T. (2000). Implementing mathematics reform: The challenge within. Educational Studies in Mathematics, 42(1), 1-34. Retrieved from https://www.jstor.org/stable/3483274

Mason, J. (2002). Qualitative researching. Thousand Oaks, CA: SAGE Publications Ltd.

Mayrath, C.M., Clarke-Midura, J., Robinson, D.H., \& Schraw, G. (2011). Technology-based assessments for $21^{\text {st }}$ century skills. USA: Information Age Publishing.

McMillan, J.H. (2003). Understanding and improving teachers' classroom assessment decision making:

implications for theory and practice. Educational Measurement: Issues and Practice, 22(4), 34-43. https://doi.org/10.1111/j.1745-3992.2003.tb00142.x

Mehrens, W. A. \& Lehmann, I. J. (1984). Measurement and evaluation in education and psychology. New York, Holt: Rinehart and Winston.

Merriam, S. (1998). Qualitative research and case study applications in education. San Francisco, CA: Jossey-Bass.

Ministry of Education and Culture. (2016). Assessment Guidelines. Jakarta: Indonesian Ministry 
of Education and Culture.

Moreland, J. P. (1998). Technology education teacher development: The importance of experiences in technological practice. Unpublished M.Ed Thesis, University of Waikato, Hamilton, New Zealand.

Moreland, J. P., \& Jones, A. (2000). Emerging assessment practices in an emergent curriculum: Implications for technology. International Journal of Technology and Design Education, 10, 283-305. Retrieved from https://link.springer.com/article/10.1023/A:1008990307060

Ortega, D. P., \& Minchalla, O. E. (2017). Assessing students in an authentic and ongoing manner in the English classroom. Theory and Practice in Language Studies, 7(3), 159-165. http://dx.doi.org/10.17507/tpls.0703.01

Pajares, M. F. (1992). Teachers beliefs and educational-research - Cleaning up a messy construct. Review of Educational Research, 62(3), 307-332. https://doi.org/10.3102/00346543062003307

Pathak, A., \& Intratat, C. (2012). Use of semi-structured interviews to investigate teacher perceptions of student collaboration. Malaysian Journal of ELT Research, 8(1), 1-12. Retrieved from https://journals.melta.org.my/index.php/majer/article/view/149/64

Patton, M.Q. (2002). Qualitative research and evaluation methods, 3rd ed. Thousand Oaks, CA: Sage Publications.

Peterson, E. R. and Irving, S.E. (2008). Secondary school students' conceptions of assessment and feedback. Learning and Instruction, 18(1), 238-250. doi:10.1016/j.learninstruc.2007.05.001

Popham, W. J. (2008). Classroom Assessment: What teachers need to know. Boston: Pearson.

Shome, S., \& Natarajan, C. (2013). Ideas of and attitudes towards projects and changing practices: Voices of four teachers. Australian Journal of Teacher Education, 38(10). http://dx.doi.org/10.14221/ajte.2013v38n10.5

Smith, M. L., Heinecke, W. \& Noble, A. J. (1999). Assessment policy and political spectacle. Teachers College Record, 101(2), 157-191.

Stiggins, R. (2001). The unfilled promise of classroom assessment. Educational Measurement: Issues and Practice, 20, 5-15. https://doi.org/10.1111/j.1745-3992.2001.tb00065.x

Strauss, A., \& Corbin, J. (1998). Basics of qualitative research: Techniques and procedures for developing grounded theory. Thousand Oaks, CA: Sage Publications, Inc.

Torrance, H. and Pryor, J. (1995). Investigating teacher assessment in infant classrooms: Methodological problems and emerging issues. Assessment in Education, 2(3), 305-320.

Williams, S. (2017). Investigating the allocation and corroboration of individual grades for projectbased learning. Studies in Educational Evaluation, 53(1), 1-9. http://dx.doi.org/10.1016/j.stueduc.2016.10.009

Yin, R. (2003). Applications of case study research (2nd ed.). Thousand Oaks, CA: Sage.

Yin, R. (2014). Case study research: Design and methods (Fifth ed.). Thousand Oaks, CA: Sage.. 